\title{
Mastering the Downward-Facing Dog: IT Flexibility and Business-IT Alignment
}

\author{
Marie Minderjahn \\ University of Amsterdam \\ marieminderjahn@gmail.com
}

\author{
Hans P. Borgman \\ University of Amsterdam \\ h.p.borgman@uva.nl
}

\author{
Hauke Heier \\ Accenture \\ hauke.heier@accenture.com
}

\begin{abstract}
With a rising quest to leverage information technologies (IT) for attaining strategic objectives, enterprises require sufficient flexibility to cope with dynamic business environments. The flexibility of IT infrastructure is investigated in this study as a mechanism to induce more aligned business and IT activities in large organizations. To complement earlier findings of IT flexibility's influence on alignment, this study operationalizes three models. Using standardized survey responses from 130 organizations from around the globe, structural equation modeling is applied. Investigating the impact of IT flexibility on alignment, we find a positive and meaningful effect of IT flexibility on alignment. Moreover, positive effects on several alignment practices are found. Although no moderating effect of cloud adoption rates is found, this study concluded with several meaningful implications to understand the strategic relevance of a flexible IT.
\end{abstract}

\section{Introduction}

Information technology (IT) has developed into a critical resource and enabler for business strategy. Advancement of IT in the business context have had the effect that the mere alignment of the IT strategies and business strategies at a functional level may no longer be sufficient. Newly emerging digital business models suggest that a fusion of business and IT strategies must take place [1]. IT has been acknowledged as a vital asset in helping organizations to survive and develop in a fastchanging environment. Enhancement of the role of IT to inform and enable business strategy has undoubtedly added to new IT investment and placed IT infrastructure models like the cloud at the center of attention.

Ongoing failure of IT to contribute to the expected business value has frequently been explained as a lack of alignment between business and IT $[2,3]$. Numerous studies have supported that strategic alignment of business and IT is linked to improve the performance of the organization, the competitive advantage, and the business value that can be realized from IT $[4,5,6]$.
Business-IT alignment (BITA) has developed into a widely researched field, but remains a top cited issue faced by executives around the world [7]. While more recent studies have contributed to a more dynamic understanding of BITA and aligning IT and business seems even more challenging in an ever-changing environment [6]. Frequent changes contribute to the expectation that IT must reflect sufficient flexibility to be responsive to changes in business demands [8]. The need for IT to provide cost-efficient and flexible infrastructure that accommodates these changes remains an open and important issue in the IS field. Changes in competition, customer demand, or prices require business and IT to systematically re-align to tailor effective responses [6]. Flexibility is found to be relevant in enhancing BITA but literature linking the constructs has been largely inconsistent $[9,10,11,12]$.

The trend of seeking higher IT flexibility is most visible in the rising popularity of cloud computing (CC) and the space it has caught in IS literature. Benefits of increased flexibility for fluctuating computing needs, scalability, speed of implementation, and low cost have placed CC high on the CIO agenda $[13,14]$. Evidence suggests that the added infrastructure flexibility characteristics of $\mathrm{CC}$ creates new enterprise value by aligning through collaboration [15]. Despite clear links with IT flexibility and BITA, a deeper understanding of $\mathrm{CC}$ in this context remains elusive. The levels at which $\mathrm{CC}$ adoption favorably strengthens the effect of IT flexibility on BITA is yet to be investigated.

Building on prior academic foundations, our study aims to address the question: How does IT flexibility affect the alignment of business and IT and how does the adoption of cloud computing moderate this relationship. We aim to address the inconsistent findings regarding the relationship of IT flexibility and BITA before we investigate in a $\mathrm{CC}$ context. Validating and empirically assessing our model through partial least squares structural equation modeling (PLS-SEM) using data from 130 global enterprises, we find meaningful evidence that IT flexibility positively influences BITA and its manifestations. Linking the constructs in a nomological network, we derive relevant implications. 


\section{Literature review}

\subsection{Business-IT Alignment}

Alignment describes 'the degree to which the needs, demands, goals, objectives, and/or structures of one component are consistent with the needs, demands, goals, objectives, and/or structures of another component' [16]. In IS literature, academics suggest that the realization of value from IT to business requires the continuous alignment of IT and business strategies [2]. BITA has persistently been cited a top IT executive concern for several decades [7]. Given the substantial empirical evidence confirming its positive effect on firm performance, productivity and growth, the ongoing alignment debate seems justified [4, 7, 17, 18].

Over time, BITA has been described as the "fit", "harmony", "fusion", or "integration" [2, 19, 20, 21]. Treating these terms synonymously, we define BITA as "the application of Information Technology in an appropriate and timely way, in harmony with business strategies, goals, and needs" [19]. Inherent to this are two roles. First, BITA harmonizes IT and business strategies, and achieves this with sufficient agility.

Accounting for an increasing environmental dynamism and constantly evolving business strategies, scholars adopted a dynamic view on BITA. Reviewing 94 studies, Jonathan et al. [7] highlighted that the majority of studies published between 2014 and 2018 put forward a dynamic perspective describing a continuous alignment process. Thereby, alignment should be maintained for the "ability to reconfigure and adapt resources to respond to a changing environment that is an important source for a firm's long-term success" [7, 22]. Maes et al. [23] defined BITA as a 'continuous process' which involved the management and design of processes to interrelate all components between business and IT in order to contribute to organizational performance. Literature has developed into an investigation of barriers and enabling mechanisms that could potentially affect the process of alignment i.e., shared domain knowledge, participation in IT and business planning, communication actors, and linked business and IT planning processes [19, 24, 25]. Dynamic economic environments, open markets, and unarguably advanced technologies have developed into a motive for sustaining BITA and demonstrate its criticality for (IT) executives today [7, 26, 27].

As more organizations are embarking on digital transformation and with the proliferation of IT, BITA has become progressively challenging to model [7]. Increasing digitalized operations firms adopt to navigate through rapid internal and external environmental dynamism reveal a need to reconsider the factors that facilitate and support continuous BITA [28]. The confirmation that IT has gained increasing momentum in shaping a digital strategy has led to a more integrated view on IT, overhauling the supportive role of IT to a complementary role in shaping business strategy. Several models to conceptualize BITA have been created over time. In the process literature, Luftman's $[19,27]$ Strategic Alignment Maturity Model (SAMM) is well received among researchers and IT practitioners alike, as a key extensions of the Strategic Alignment Model by Henderson and Venkatraman. The model has been revisited most recently and validated by nearly 400 Fortune 500 companies and 3000 participants demonstrating a well-balanced and valid instrument. The SAMM model suggests six dimensions communication, partnerships, governance, value measurement, scope and architecture, and skills - which shape the level of alignment maturity and provide a set of practices that can be nurtured for alignment [19, 27].

\subsection{IT Flexibility}

With the rising importance of information technology (IT) to support strategic objectives, the challenges of IT investments have shifted to support both present and future applications - by offering sufficient flexibility. IT infrastructure as an organizational resource moved more and more to the forefront of this discussion, being defined as "a set of shared IT resources which is a foundation for both communication across the organization and the implementation of present/future business applications" $[8,29]$. Early work has described a robust and flexible IT as an organizational core competency [8, 21, 29, 30].

IT infrastructure consists of IT components (computing technology, hardware, software) which provision the delivery of shared IT services i.e., electronic data interchange or corporate databases. Subsequently, IT infrastructure provisions the functionality for business applications which are employed to enable and execute business processes and strategy [21]. Failure to align business and IT could subsequently present itself in an ineffective IT system that is unsupportive of business objectives and strategy.

As uncertain and dynamic environments are fraught with risks, organizations seek to understand how much flexibility to add to their IT infrastructure to maintain consistently high alignment. And while Luftman had adopted IT flexibility in the IT scope and architecture dimension of the SAMM model $[19,27]$, the underlying mechanism by which IT flexibility supports alignment was not theoretically or empirically addressed.

In 2011, Tallon and Pinsonneault [6] found that IT flexibility and alignment to behave as complementary capabilities in enhancing organizational agility in rapidly changing environments. Tian et al. [31] 
complemented these findings highlighting that the relationship between BITA and competitive advantage is significantly shaped by IT flexibility and the relationship between business and IT. Subsequently, it seems to be widely acknowledged that IT flexibility must demonstrate a significant influence on aligning business and IT. Nevertheless, when modeling the direct relationship between IT flexibility and BITA, there has been an incongruence in the underlying mechanisms.

Prior studies largely conceptualized IT flexibility using the modularity, connectivity and compatibility dimensions suggested by Duncan [8]. In a study of 202 IT executives, Chung et al. [9] found support for connectivity and modularity to positively influence alignment, not, however, for compatibility. In contrast, Jorfi et al. [11] found support for connectivity to enhance BITA but lacked evidence for the modularity and compatibility of IT systems. The authors argued that information sharing across IT components and applications facilitates better communication and enables more rapid design of responses. Interestingly, both studies investigated BITA as a broad construct and did not delineate specific alignment practices that benefit from IT flexibility [9, 11, 27]. Isal et al. [10] adopted the SAMM dimensions but only found support for compatibility to influence BITA, not for connectivity nor modularity. Moreover, the latter two studies reflected on firms in developing countries which limits the generalizability to developed regions $[10,11]$.

In a review of commonly used IT flexibility dimensions, Chanopas et al. [32] demonstrate that the original dimensions of connectivity, compatibility, and modularity do not exhaustively capture the IT flexibility requirements that are placed on modern IT systems to effectively cope with today's IT requirements and turbulent environments. The review has subsequently born the reconceptualization of IT flexibility into more refined and practice-oriented properties. (1) Loose coupling, (2) standardization, (3) transparency, and (4) scalability characterize a flexible IT that is able to adjust to changing business and IT strategies [8, 29, 32]. These qualities have recently developed into dominantly used and validated subconstructs of a flexible IT $[33,34]$.

While a flexible IT may support the development of cost-effective products and services, it can also contribute to growth and competitiveness by allowing higher speed in the development of initiatives and innovation [21]. Conversely, inflexibility of an IT system may be reflected in the "difficulty developers have with the users' demands that require systems to do what they were not designed to do" - the unplanned system requirements that emerge as environments change and demand flexible responses by business and IT [8]. Flexibility has long been of substantial concern particularly in management literature as it has put forward the ability to handle a greater variety of market and business needs and has generally been applied to all major disciplines such as finance, manufacturing or human resources $[32,35,36]$. With the rising role of IT for business strategy, it is thus of vital importance to address the concern for a flexible IT and its benefits in supporting business objectives. Subsequently, IT executives are confronted with the need to invest in flexible IT infrastructure and develop architectures that can support current and future business applications.

As central thesis in this study, it is conceivable that the sum of the four qualities i.e., loose coupling, standardization, transparency, and scalability, make IT sufficiently flexible to provision alignment between the IT and business functions in designing effective ITenabled responses to changing requirements. First, a flexible IT is more likely to sustain an aligned fit between business and IT allowing to better reconfigure and adapt IT resources to value chain activities to support business strategy [11]. Second, IT becomes more responsive to changing opportunities and innovations the business functions encounter as the infrastructure allows for modifications [8, 29]. The prescribed properties allow IT to accommodate rapid adaptations to system component, without compromising the interoperability in other applications. At the same time, the properties enhance the innovative potential at an application-level by mitigating disruptions. Based on the foregoing discussion, we expect that greater IT flexibility will facilitate higher levels of BITA. We propose H1: IT flexibility has a positive impact on business-IT Alignment.

Adopting a process perspective of BITA, we further argue that the mechanisms underlying the effect of IT flexibility is best understood by considering activities which form alignment. We aim to resolve the inconsistent and abstract analysis of BITA in past literature by pointing at the individual effects of IT flexibility on an activity-based level to further understand reasons for the past inconsistencies. Jentsch et al. [37] found a clearly delineated relationship between heightened shared understanding from loosely coupled IT processes, although, conditioned by a flexible IT infrastructure. We posit H1a: IT flexibility positively influences the dimension of communication.

The promotion of transparency exhibits an especially strong effect on the formation of business and IT liaison. According to Hagel and Brown [38], transparent IT systems i.e., web-based services, allow for flexible communication and promote collaborative work formation by exposing mutual capabilities, a shared understanding and foster joint solution development. We hypothesize that $\boldsymbol{H 1 b}$ : IT flexibility positively influences the dimension of partnership.

With an inherent application transparency and 
interface standardization, we posit that IT value measurement is enhanced by a flexible IT, as IT's value contribution and performance is more demonstrable and accountable [27]. H1c: IT flexibility positively influences the dimension of value measurement.

Finally, we posit that a flexible IT infrastructure contributes to more integrated governance practices that are characterized by shared decision-making authority and strategic planning of business and IT. Mikalef et al. [12] found that a flexible IT infrastructure that is decomposable into IT subsystems and shared standards facilitate decentralized and responsive decision making concerning IT resources. A flexible IT infrastructure may subsequently equip business units to better coordinate change by modifying or creating applications that address emerging opportunities without compromising other IT systems [6]. H1d: IT flexibility positively influences the dimension of governance.

\subsection{Cloud Computing}

Cloud computing (CC) is widely advocated to alleviate the tensions between IT service supply and business demands under conditions of fierce competition, limited IT budgets, and turbulent environments which demand a flexible IT service provision [13]. Considered a new method for the delivery of computing services, $\mathrm{CC}$ is based on technologies like grid computing, service-oriented architecture, and virtualization. The National Institute of Standards and Technology define $\mathrm{CC}$ as "a model for enabling ubiquitous, convenient, on-demand network access to a shared pool of configurable computing resources (e.g., networks, servers, storage, applications, and services) that can be rapidly provisioned and released with minimal management effort" [39]. CC gained significant space in IS research by promoting benefits of higher flexibility, speed of implementation, access, scalability, and low cost $[13,14,40]$.

To stay competitive, organization seek the deployment of flexible infrastructures which are capable of converging business and IT to work in concert, achieve higher business value, productivity and responsiveness [41]. Studies also identified benefits of increased flexibility, implementation speed, access, scalability, and low cost $[13,14,41]$. By reducing idle resources, CC offers quicker delivery of applications and solutions within budget, scope, and time with flexibility in the use of those resources. Iyer and Henderson [42] linked the realization of CC benefits like increased business focus, reusable infrastructure, and collective problem solving, to the adoption of CC.

Extant research supports to the idea that $\mathrm{CC}$ contributes to IT flexibility by linking individual characteristics of $\mathrm{CC}$ such as elasticity, ubiquitous access, scalability, and pay-per-use to increased IT flexibility $[15,44]$. A qualitative study conducted by Lal and Bharadwaj [44] differentiated the cloud service models in the flexibility debate, namely Software-as-aService (SaaS), Platform-as-a-service (PaaS) and Infrastructure-as-a-service (IaaS). Accordingly, SaaS offers flexibility through on-demand subscription models, replacing the need to purchase, maintain, or upgrade applications themselves. PaaS offers flexibility by focusing organizational resources on development or deployment activities through means of cloud-based tools and without the need to maintain the infrastructure. Lastly, IaaS offers flexible provisioning of server capacity, storage and networking structure on-demand, freeing resources from managing the physical IT infrastructure. Investigating dimensions such as economic, process, performance and market flexibility, the authors [44] found that cloud services enhance organizational flexibility regardless of the service model in use,. Wulf et al. [45] elicited that the adoption of the cloud service models is manifested in different needs for flexibility. IaaS adoption is thus motivated by gained flexibility in provisioning infrastructure. PaaS adoption is motivated by flexibility to access specialized IT resources i.e., for building, testing, and scaling applications. SaaS adoption, on the other hand, offers flexibility to focus on core competencies and reduce internal efforts by outsourcing development activities.

While findings suggested that organizational flexibility is associated with enhanced alignment of IT with business objectives, BITA was not specifically measured in these studies. Fuzes [46] argues that flexibility gains derived from cloud adoption unarguably add to alignment as IT becomes more responsive to changing business needs with shorter development cycles and a more elastic IT infrastructure. Subsequently, the strategic role and integration of IT for business goals is reflected in more optimized BITA.

The influence of cloud-based service models has also been discussed concerning weaker alignment of business and IT as CC adoption enhances shadow IT activities which refer to the use of hardware, software, or services used in an organization without explicit approval. Shadow IT poses substantial security and compliance threats and undermines the possibility of a flexible IT by neglecting integration, compliance, and interoperability [47]. The lack of alignment between business and IT has most often been cited as a reason for emerging shadow IT, enforced by a lack of communication, untransparent IT development processes, and delayed response time by IT to fulfil user requests [48]. A recent Accenture survey has investigating cloud adoption found that misalignment of business and IT are frequently reported as a barrier to realize business value from $\mathrm{CC}$ among high adopters 
[49]. The lack of cloud skills and application sprawl are reported as barriers by both medium and high adopters, hinting at a deterioration of BITA [49].

To better understand IT flexibility's influence on alignment, we delineate how different levels of CC may affect the positive effects of IT flexibility on BITA. Based on the literature, we expect that high $\mathrm{CC}$ adoption does not only reflect high IT flexibility but also enhances BITA by providing higher IT responsiveness and strategic integration under $\mathrm{CC}$ adoption. We hypothesize $\boldsymbol{H 2}$ : The relationship between IT flexibility on business-IT alignment is moderated by the degree of cloud adoption so that the effect is stronger for organizations with high cloud adoption.

\section{Research Methods}

\subsection{Data Collection}

Data from 145 organizations was gathered through a standardized survey. The survey was distributed by a research agency and through LinkedIn applying a purposive sampling strategy that yielded response rates

Table 1. Sample demographics $(n=130)$

\begin{tabular}{|c|c|c|}
\hline Industry & $\mathrm{n}$ & $\%$ \\
\hline Automotive & 6 & 4.6 \\
\hline Banking & 8 & 6.2 \\
\hline Capital Markets & 3 & 2.3 \\
\hline Chemicals & 5 & 3.8 \\
\hline Communications \& Media & 4 & 3.1 \\
\hline Consumer Goods \& Services & 4 & 3.1 \\
\hline Energy & 7 & 5.4 \\
\hline Health & 9 & 6.9 \\
\hline High Tech & 10 & 7.7 \\
\hline Industrial equipment & 6 & 4.6 \\
\hline Insurance & 9 & 6.9 \\
\hline Life Sciences & 7 & 5.4 \\
\hline Natural Resources & 5 & 3.8 \\
\hline Public Services & 3 & 2.3 \\
\hline Retail & 10 & 7.7 \\
\hline Software \& Platforms & 12 & 9.2 \\
\hline Travel & 6 & 4.6 \\
\hline Utilities & 6 & 4.6 \\
\hline Other & 10 & 7.7 \\
\hline \multicolumn{3}{|l|}{ Firm size (annual revenue) } \\
\hline$\$ 1-\$ 4.9$ billion & 25 & 19.2 \\
\hline$\$ 5-\$ 9.9$ billion & 47 & 36.2 \\
\hline$\$ 10-\$ 19.9$ billion & 56 & 43.1 \\
\hline$\$ 20$ billion or more & 2 & 1.5 \\
\hline \multicolumn{3}{|l|}{ Geographic region } \\
\hline North America & 26 & 20 \\
\hline Europe & 59 & 45.4 \\
\hline Latin America & 20 & 15.4 \\
\hline Asia Pacific & 25 & 19.2 \\
\hline
\end{tabular}

of $33.3 \%$ and $21 \%$ respectively. After eliminating incomplete data $(>5 \%), 130$ responses remained for analysis. For the sample senior IT executives were identified as key informants due to in-depth knowledge about the IT infrastructure and processes. Subsequently, $36.9 \%$ of responses were collected from Chief Information Officers, $42.3 \%$ from Chief Technology Officers, $10 \%$ from Chief Data Officers, $1.5 \%$ from Chief Analytics Officers, 5.4\% from CIOs minus one level, and 3.8\% from Directors/ Vice-Presidents. The organizations reflected a variety of industries and geographic diversity. $20 \%$ of organizations are headquartered in North America, 45.5\% in Europe, $15.4 \%$ in Latin America, and $19.2 \%$ in Asia Pacific (Table 1). Large organizations ( $>\$ 1$ billion revenue) from various industries were selected to seek generalizability and due to a commonly higher information-intensity, more elaborate IT governance mechanisms, and active alignment practices [11].

The minimum sample size of 63 was obtained a priori using $\mathrm{G}^{*}$ Power software. The final sample of 130 responses was considered adequate to be processed [50]. Harman's single factor test was applied to test for common method bias [51]. All items were entered into a principal component analysis with unrotated factors to attest that no single unrotated factor accounted for more than $50 \%$ of the co-variation. Results indicate that common method bias was not an issue as a single unrotated factor explained only $15.19 \%$ of variation.

\subsection{Model Specification}

For the measurement model, we relied on existing conceptualizations of IT flexibility and BITA such that items had been validated in prior literature.

IT flexibility measurement was adapted from prior literature and was modeled as a reflective-formative second-order construct [33]. First-order reflective dimensions measured are (1) loose coupling [LC], (2) standardization [STND], (3) transparency [TRNS], and (4) scalability [SCAL $][8,29,32]$. In total, 19 items captured the four first-order dimensions. Respondents evaluated on a five-point Likert scale the extent to which they agreed or disagreed with a given statement.

Based on Luftman's SAMM, BITA was modeled as reflective-formative second-order construct through four formative dimensions: (1) communication [COM], (2) partnerships [PRTN], (3) value measurement [VALUE] and (4) IT governance [GOV], each measured by three reflective items respectively [27].

With a strong emphasis on observable functional alignment activities, Luftman's skills dimension was excluded from the instrument as it reflects most strongly the developmental capabilities of an organization. Due to endogeneity concerns with the IT flexibility variable, 
the scope and architecture dimension was also eliminated. Nevertheless, the four selected dimensions were determined to capture the social and intellectual properties of BITA and to reduce the survey length and associated biases. Respondents were asked to indicate which of five statements most closely reflected their practices on a five-point Likert-type scale.

The degree of cloud adoption is measured on a fivepoint Likert-type scale. Respondents were asked to rate their CC adoption i.e., proportion of applications moved to the cloud, concerning SaaS, PaaS, or IaaS cloud service models. This measurement was based on expert knowledge that organizations rarely employ a single $\mathrm{CC}$ model and that $\mathrm{CC}$ adoption would most accurately be reflected in their adoption of each service.

Control variables were used to account for differences in firm size and geographic location.

Prior to administering the survey, five IT executives pre-tested it to identify issues with wordings and comprehensiveness to ensure content and face validity.

\section{Results}

The measurement and structural models were evaluated via PLS-SEM analysis using SmartPLS. Motivation to apply PLS-SEM stems from its suitability to evaluate formative higher-order constructs characterized by high complexity. While robust with small sample sizes PLS poses minimum normal distribution requirements. The PLS-SEM analysis followed two steps: (1) the evaluation of the measurement model prior to (2) testing the causal relationships of the structural model.

\subsection{Measurement Model Validation}

The first-order reflective constructs were evaluated by construct reliability (item reliability, internal consistency), convergent validity and discriminant validity. Item reliability was tested by examining if construct-to-item loadings were above the threshold of 0.7 [52]. Items with lower loadings were omitted to the point where composite reliability did not improve and exceeded 0.7. Convergent validity was found by confirming that the AVE is above the lower limit of 0.5 [52]. To assess discriminant validity, we examined AVE and inter-construct correlations. The square root of the AVE of each construct is larger than the correlations of the construct with other constructs and inter-construct correlations were well below the threshold of 0.9 and discriminant validity therefore established [50, 52]. Diagonal figures in Table 2 show that the square root of AVE exceeds off-diagonal inter-construct correlations.

Second-order formative constructs were assessed by examining the predictive validity and testing for multicollinearity of formative indicators. Applying nonparametric bootstrapping with 5000 iterations, the weights were calculated. All weights were significant [0.201 - 0.372] at a $1 \%$ level suggesting indicator validity. Multicollinearity was tested through the variance inflation factor (VIF) to determine the degree to which other formative indicators related to the same construct affect any formative indicator. All VIF values were well below the liberal threshold of 10 and below the conservative threshold of 3.3 [1.097 - 3.134].

The results of the analysis suggest each LOC is an important determinant of their HOC. The goodness of fit was applied using the standardized root mean square residual (SRMR). The SRMS of 0.04 indicated good fit with upper confidence intervals sufficiently below 0.1 .

\subsection{Structural Model Evaluation}

We assessed the structural models through the explained variance of endogenous variables $\left(\mathrm{R}^{2}\right)$, path coefficients $(\beta)$, corresponding $p$-values, and the effect sizes $\left(f^{2}\right)$ [50]. Results are reported in Figure 1. Organizational size and geographic region were applied as control variables. The moderating effect of cloud adoption was assessed in accordance to the two-step approach by Hair et al. [53]. First, direct models (A, B) were assessed before testing a moderation model (C).

Prior to assessing the structural models, VIF values were computed to ensure the absence of collinearity issues by a threshold of $3.3(1.028-1.936)$. To assess the direct and indirect path models, three analyses were performed: (A) a direct model with BITA as a HOC, (B)

Table 2. Validity and reliability statistics and correlations

\begin{tabular}{llllllllllll}
\hline Construct & CR & AVE & 1 & 2 & 3 & 4 & 5 & 6 & 7 & 8 & 9 \\
\hline COM & 0.829 & 0.618 & 0.786 & & & & & & & & \\
CLOUD & 0.849 & 0.660 & -0.03 & 0.812 & & & & & & & \\
GOV & 0.737 & 0.590 & 0.572 & -0.02 & 0.768 & & & & & & \\
LC & 0.888 & 0.725 & 0.194 & 0.358 & 0.254 & 0.852 & & & & & \\
PRTN & 0.851 & 0.656 & 0.553 & 0.051 & 0.626 & 0.325 & 0.810 & & & & \\
SCAL & 0.816 & 0.527 & 0.072 & 0.233 & 0.202 & 0.583 & 0.266 & 0.726 & & & \\
STND & 0.779 & 0.550 & 0.056 & 0.120 & 0.09 & 0.432 & 0.158 & 0.386 & 0.742 & & \\
TRNS & 0.834 & 0.627 & 0.164 & 0.345 & 0.251 & 0.748 & 0.316 & 0.525 & 0.634 & 0.792 & \\
VALUE & 0.827 & 0.621 & 0.552 & -0.085 & 0.504 & 0.365 & 0.540 & 0.266 & 0.265 & 0.388 & 0.788 \\
\hline
\end{tabular}


a direct model without BITA as a $\mathrm{HOC}$ and (C) a moderation model using the HOC (Figure 1). To test the causal paths of the structural models, a bootstrapping approach using 5000 re-samples was employed.

A positive and significant path coefficient confirms that IT flexibility positively influences BITA $(\beta=0.429$, $\mathrm{p}<0.001, \mathrm{f}^{2}=0.247$ ). As IT flexibility increases, BITA is positively enhanced with a moderate effect strength. In the direct model $\mathrm{A}$, the control variable geographic region shows a significant $\left(\beta=0.209, \mathrm{p}<0.05, \mathrm{f}^{2}=\right.$ 0.058 ), yet unmeaningful and small effect while firm size is insignificant $(\beta=0.162, p>0.05)$. Assessing H1a to H1d, we find that IT flexibility positively influences communication $(\beta=0.238, \mathrm{p}<0.05)$, value measurement $(\beta=0.391, p<0.001)$, partnerships $(\beta=$ $0.331, \mathrm{p}<0.000)$ and IT governance $(\beta=0.265, \mathrm{p}<$ $0.001)$. The strongest effect is found on partnerships $\left(\mathrm{f}^{2}\right.$ $=0.130)$ and value measurement $\left(\mathrm{f}^{2}=0.193\right)$. Communication $\left(\mathrm{f}^{2}=0.064\right)$ and IT governance $\left(\mathrm{f}^{2}=\right.$ 0.080 ) indicate very small effect sizes. No significant effect is found for the control variables.

The interaction between cloud adoption degree and BITA is insignificant, showing that the relationships between IT flexibility and BITA is not significantly strengthened under the presence of high cloud adoption $(\beta=-0.069, p>0.05)$. Thus, $\mathrm{H} 2$ is not supported and a negative coefficient instead of a positive coefficient is found. Geographic region shows a significant but negligible effect $\left(\beta=0.200, p<0.05, f^{2}=0.057\right)$ while firm size does not significantly affect BITA.

The predictive capacity $\left(\mathrm{R}^{2}\right)$ of the models show that IT flexibility explains $27.3 \%$ of variance in BITA
$\left(\mathrm{R}^{2}=0.273\right), 13.5 \%$ of variance in communication $\left(\mathrm{R}^{2}=\right.$ $0.135), 23.1 \%$ in value measurement $\left(\mathrm{R}^{2}=0.231\right)$, $17.7 \%$ in partnerships $\left(\mathrm{R}^{2}=0.177\right)$, and $14.3 \%$ in IT governance $\left(\mathrm{R}^{2}=0.143\right)$. The moderated model $\mathrm{C}$ explains $31.5 \%$ of BITA's variance $\left(\mathrm{R}^{2}=0.315\right)$.

\section{Discussion}

The identification of IT flexibility as a facilitator for BITA is an important finding at a time where the strategic role of IT is at the forefront of IS research. Particularly the negative, yet insignificant findings on the role of $\mathrm{CC}$ in this relationship demonstrates the trade-off organizations experience as they adopt new flexibility-associated technologies. Our results support the importance of designing sufficiently flexible IT systems to maintain alignment. To date, BITA remains a highly aspired but challenging process. Designing an organization's IT system with sufficient degrees of flexibility to accommodate for reactive capacity and efficient use of resources was found to not only improve overall BITA, but we were able to delineate specific enhanced alignment practices.

Our study extends a current body of literature which has related attributes of IT flexibility to BITA with inconsistent results such that some studies stress the role of modularity and others the role of compatibility or connectivity $[9,10,11]$. Our study complements these studies by validating the four properties i.e., loose coupling, standardization, transparency, and scalability, which together enhance BITA.

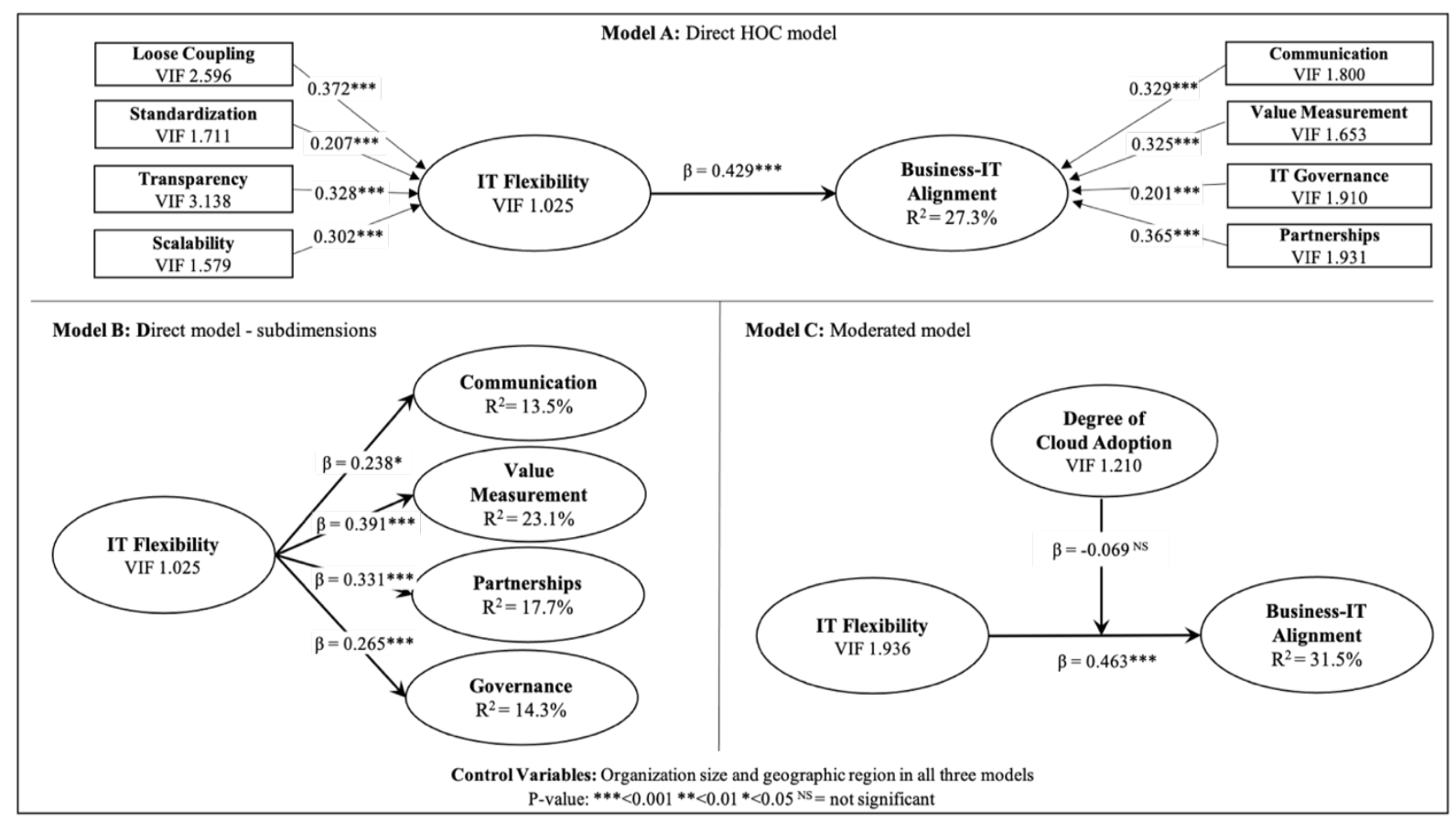

Figure 1: Results of the structural model evaluation 
Additionally, the study provides further insights on the role of IT infrastructure in maintaining strategic alignment. We confirm hypotheses of prior literature of a causal link between IT flexibility and enhanced BITA. Results of the PLS analysis confirm that IT flexibility explains a moderate amount of $31.2 \%$ variance in BITA activities. One compelling finding is that IT flexibility demonstrates the largest effect on the value measurement. This signals that the contribution of the IT organization to business is enhanced or at least better understood through a flexible IT setup [27]. One of the core issues in IS literature has long been the inability of organizations to measure the business value from IT projects which seems to be supported through higher degrees of transparency, standardization, modularity and scalability in the system design [3].

These findings are in line with a moderate effect of IT flexibility on the partnership formation between business and IT. Flexible IT structures seem to support the formation of mutual trust, risk sharing and realistic expectations between business and IT functions. The small effect of IT flexibility on communication stressed the enhanced quality for business and IT in sharing ideas, knowledge and information and contributes to a mutual understanding of each other's risks, priorities, needs and most importantly strategic goals [27]. This communication is paramount to the integration and coordination of strategic activities within the enterprise and with external partners to leverage IT resources effectively and build competitive advantage [27]. This trend is also reflected in slightly enriched IT governance. It is conceivable that a flexible IT design contributes to a more systematic integration of the IT function in strategic planning and demonstrates more direct investment due to the increased understanding and decreased complexity of IT for business planning.

The degree of CC adoption does not yield a positive effect on IT flexibility in fostering alignment, and unexpectedly demonstrates a small and insignificant, yet negative coefficient. A possible explanation is that $\mathrm{CC}$ adoption introduces a third stakeholder i.e., the CC provider, with a subsequent need for more alignment and formalization of management processes. In addition, a migrated IT landscape needs to conform with the providers' CC architecture which may limit architectural freedom. CC adoption may also condition a new conceptualization of BITA [54]. As IT becomes responsible for overlooking and administering servicelevel agreements with providers, there might be a new role spanning dimension to which IT is capable of effectively translating enterprise needs to providers and bridging a strategic link to an outsourced IT [55].

Nevertheless, the study raises several managerial implications particularly within the debate on how executives can better support continuous BITA in their organizations [26]. Our results suggest that IT flexibility on its own positively enhances BITA and associated activities such that investing in a more flexible IT infrastructure may be associated with several benefits in terms of strategic agility. IT and business executives can use this information to organize for a more flexible IT i.e., by adopting service-oriented IT architecture [56]. To reduce complexity within their IT system to handle heterogenous user requests, increasingly higher workloads and system complexity, CIOs can organize the IT function for more flexibility through loosely coupled, transparent, standardized, and scalable systems that can adapt easily to business user needs. Additionally, managers should provision organizational structures to benefit from IT flexibility, such as to account for new IT value measurement strategies, acknowledgement of more efficient IT resource utilization through modular system allocation and more effective collaboration between IT and business.

\section{Conclusion and Limitations}

This study tested and extended existing conceptualization on the causal relationship between a flexible IT design and BITA and applied this model to a cloud computing context. Findings should contribute to a better understanding of the role and importance of organizing not only for agility in business processes but IT processes alike to support a more effective strategic orientation and fulfillment of business needs through IT.

Against significant findings, our study is constrained by several limitations which future research could address. To reduce survey length and focus the hypotheses, measurement of BITA was limited to four of six dimensions [27]. Two dimensions remain overlooked and may require investigation in an extended study design. While we investigated the moderation of cloud adoption degrees, we were unable to test for a significant effect. Thus, the role of $\mathrm{CC}$ demands further investigation to understand how it may influence IT flexibility's impact on BITA. Additionally, the investigation of the role of $\mathrm{CC}$ on a sub-dimensional level of BITA was outside the scope of this study based on added complexity. Further moderation analysis of $\mathrm{CC}$ could have yielded meaningful theoretical implications to understand under which degrees of cloud adoption the organizational dimensions suffer from misalignment. Cloud adoption may benefit from alternate operationalizations than an inference from service model adoption. Future research may also consider modeling CC as antecedent of IT flexibility rather than a moderator.

Despite the view that alignment is a continuous, never-ending process, we measured business-IT alignment at a single point in time. Using longitudinal 
data, future research could explore whether alignment changes over time under conditions of a flexible IT infrastructure or maturing degrees of cloud adoption. Here, a multi-respondent approach could also significantly enhance findings as compared to our single-respondent approach, as biases from IT may be uncovered through the confirmation or rejection of alignment practices by business executives. Although we controlled for different organizational sizes and geographic regions, future research could also address the differences between these groups more closely. Using larger sample sizes and organizations of small or medium sizes could identify differences across groups and could greatly contribute to the generalizability of findings. Lastly, future research could also identify more closely and qualitatively the types of activities and practices that take place on a regular basis through an in-depth analysis of how a flexible IT impacts internal processes and practices within organizations. This practice-based approach could derive more actionable insights on best-practices and ways of improvement.

\section{References}

[1] Bharadwaj, A., O. El Sawy, P. Pavlou, and N. Venkatraman, "Digital Business Strategy: Toward a Next Generation of Insights", MIS Quarterly 37(2), 2013, pp. 471-482.

[2] Henderson, C., and N. Venkatraman, "Strategic alignment: Leveraging information technology for transforming organizations", IBM Systems Journal 32(1), 1993, pp. 4 16.

[3] De Haes, S., W. Van Grembergen, A. Joshi, and T. Huygh, Enterprise Governance of Information Technology: Achieving Alignment and Value in Digital Organizations, Springer Nature, 2019.

[4] Coltman, T., P. Tallon, R. Sharma, and M. Queiroz, "Strategic IT Alignment: Twenty-Five Years on", Journal of Information Technology 30(2), 2015, pp. 91100.

[5] Gerow, J.E., J.B. Thatcher, and V. Grover, "Six types of IT-business strategic alignment: an investigation of the constructs and their measurement", European Journal of Information Systems 24(5), 2015, pp. 465-491.

[6] Tallon, P., and A. Pinsonneault, "Competing perspectives on the link between strategic information technology alignment and organizational agility: insights from a mediation model", MIS Quarterly 35(2), 2011, pp. 463484.

[7] Jonathan, G.M., L. Rusu, and E. Perjons, "Business-IT Alignment in the Era of Digital Transformation: Quo Vadis?", Hawaii International Conference on System Sciences (HICSS), Maui, Hawaii, USA, January 7-10, 2020, (2020), 5563-5572.

[8] Duncan, N.B., "Capturing Flexibility of Information Technology Infrastructure: A Study of Resource Characteristics and Their Measure", Journal of management information systems 12(2), 1995, pp. 37-57.
[9] Chung, S., R. Rainer, and B. Lewis, "The Impact of Information Technology Infrastructure Flexibility on Strategic Alignment and Application Implementations", Communications of the Association for Information Systems 11(1), 2003.

[10] Isal, Y., G. Pikarti, A. Hidayanto, and E. Putra, "Analysis of IT infrastructure flexibility impacts on IT-Business strategic alignment", Journal of Industrial Engineering and Management 9(3), 2016, pp. 657-683.

[11] Jorfi, S., K.M. Nor, and L. Najjar, "An empirical study of the role of IT flexibility and IT capability in IT-business strategic alignment", Journal of Systems and Information Technology 19(1/2), 2017, pp. 2-21.

[12] Mikalef, P., A. Pateli, and R. van de Wetering, "IT architecture flexibility and IT governance decentralisation as drivers of IT-enabled dynamic capabilities and competitive performance: The moderating effect of the external environment", European Journal of Information Systems, 2020, pp. 129.

[13] Armbrust, M., A. Fox, R. Griffith, et al., "A View of Cloud Computing”, Commun. ACM 53(4), 2010, pp. 5058.

[14] Chebrolu, S.B., "Assessing the relationships among cloud adoption, strategic alignment and IT effectiveness", Journal of Information Technology Management 22(2), 2011, pp. 13-29.

[15] Liu, S., F. Chan, J. Yang, and B. Niu, "Understanding the effect of cloud computing on organizational agility: An empirical examination", International Journal of Information Management 43, 2018, pp. 98-111.

[16] Nadler, D.A., and M.L. Tushman, "A model for diagnosing organizational behavior", Organizational Dynamics 9(2), 1980, pp. 35-51.

[17] Sabherwal, R., J.B. Thatcher, and Y.E. Chan, "Antecedents and outcomes of strategic IS alignment: an empirical investigation", IEEE Transactions on Engineering Management 53(1), 2006, pp. 27-47.

[18] Wu, S.P.-J., D.W. Straub, and T.-P. Liang, "How information technology governance mechanisms and strategic alignment influence organizational performance: Insights from a matched survey of business and IT managers", MIS quarterly 39(2), 2015, pp. 497518.

[19] Luftman, J., "Assessing Business-IT Alignment Maturity", Communications of the Association for Information Systems 4(1), 2000.

[20] Smaczny, T., "Is an alignment between business and information technology the appropriate paradigm to manage it in today's organisations?", Management Decision 39(10), 2001, pp. 797-802.

[21] Weill, P., and M. Broadbent, "Management by Maxim: How Business and IT Managers Can Create IT Infrastructures", MIT Sloan Management Review 38, 1997, 77-92.

[22] Wagner, H.-T., "Evolvement of business-IT alignment over time: A situated change perspective", 2014 47th Hawaii International Conference on System Sciences, IEEE (2014), 4366-4375.

[23] Maes, R., D. Rijsenbrij, O. Truijens, and H. Goedvolk, "Redefining business-IT alignment through a unified 
framework", Universiteit Van Amsterdam/Cap Gemini White Paper, 2000.

[24] Chan, Y.E., R. Sabherwal, and J.B. Thatcher, "Antecedents and outcomes of strategic IS alignment: an empirical investigation", IEEE Transactions on Engineering Management 53(1), 2006, pp. 27-47.

[25] Reich, B.H., and I. Benbasat, "Factors that influence the social dimension of alignment between business and information technology objectives", MIS quarterly 24(1), 2000, pp. 81-113.

[26] Kappelman, L., V.J.L, C. Maurer, et al., "The 2019 SIM IT Issues and Trends Study", MIS quarterly executive 19(1), 2020, pp. 69-104.

[27] Luftman, J., K. Lyytinen, and T. Ben Zvi, "Enhancing the measurement of information technology (IT) business alignment and its influence on company performance", Journal of Information Technology 32(1), 2017, pp. 2646.

[28] Yeow, A., C. Soh, and R. Hansen, "Aligning with new digital strategy: A dynamic capabilities approach", The Journal of Strategic Information Systems 27(1), 2018, pp. 43-58.

[29] Byrd, T.A., and D.E. Turner, "Measuring the Flexibility of Information Technology Infrastructure: Exploratory Analysis of a Construct", Journal of Management Information Systems 17(1), 2000, pp. 167-208.

[30] Davenport and Linder, "Information management infrastructure: the new competitive weapon?", 1994 Proceedings of the Twenty-Seventh Hawaii International Conference on System Sciences, (1994), 885-896.

[31] Tian, J., K. Wang, Y. Chen, and B. Johansson, "From IT deployment capabilities to competitive advantage: An exploratory study in China", Information Systems Frontiers 12(3), 2010, pp. 239-255.

[32] Chanopas, A., D. Krairit, and D. Ba Khang, "Managing information technology infrastructure: A new flexibility framework", Management Research News 29(10), 2006, pp. 632-651.

[33] Mikalef, P., A. Pateli, and R. van de Wetering, "IT Flexibility and Competitive Performance: The mediating role of IT-enabled dynamic capabilities", (2016).

[34] Tafti, A., S. Mithas, and M.S. Krishnan, "The Effect of Information Technology-Enabled Flexibility on Formation and Market Value of Alliances", Management Science 59(1), 2012, pp. 207-225.

[35] De Leeuw, A.C.J., and H.W. Volberda, "On the concept of flexibility: A dual control perspective", Omega 24(2), 1996, pp. 121-139.

[36] Golden, W., and P. Powell, "Towards a definition of flexibility: in search of the Holy Grail?", Omega 28(4), 2000, pp. 373-384.

[37] Jentsch, C., A. Reitz, and D. Beimborn, Templates for joined work systems - How business process modularity and IT flexibility enable mutual understanding among business and IT, 2017.

[38] Hagel, J., and J.S. Brown, "Your Next IT Strategy", Harvard Business Review, 2001. https://hbr.org/2001/10/your-next-it-strategy

[39] Mell, P., and T. Grance, "The NIST definition of cloud computing", National Institute of Standards and Technology 53, 2011.
[40] Dutta, A., G.C. Peng, and A. Choudhary, "Risks in enterprise cloud computing: the perspective of IT experts", Journal of Computer Information Systems 53(4), 2013, pp. 39-48.

[41] Luo, X., W. Zhang, R. Bose, H. Li, and Q.B. Chung, "Producing competitive advantage from an infrastructure technology: The case of cloud computing", Information Systems Management 35(2), 2018, pp. 147-160.

[42] Iyer, B., and J. Henderson, "Business Value from Clouds: Learning from Users", MIS Quarterly Executive 11(1), 2012.

[43] Srinivasan, S., "Is security realistic in cloud computing?", Journal of International Technology and Information Management 22(4), 2013, pp. 3.

[44] Lal, P., and S.S. Bharadwaj, "Understanding the impact of cloud-based services adoption on organizational flexibility: An exploratory study", Journal of enterprise information management 29(4), 2016, pp. 566-588.

[45] Wulf, F., T. Lindner, S. Strahringer, and M. Westner, "IaaS, PaaS, or SaaS? The Why of Cloud Computing Delivery Model Selection -Vignettes on the PostAdoption of Cloud Computing", (2021).

[46] Fuzes, P., "How Does Cloud Computing Change the Strategic Alignment Between Business and IT?", Conference on Digital Information Processing, (2018).

[47] Zimmermann, S., C. Rentrop, and C. Felden, "A Multiple Case Study on the Nature and Management of Shadow Information Technology", Journal of Information Systems 31, 2017, pp. 79-101.

[48] Thatte, S., and N. Grainger, "Feral Systems: Why users write them and how they add value", (2010).

[49] Accenture, Sky-high hopes: Reach cloud migration's full value, 2020.

[50] Hair, J.F., G.T.M. Hult, C. Ringle, and M. Sarstedt, $A$ primer on partial least squares structural equation modeling (PLS-SEM), Sage publications, 2016.

[51] Podsakoff, P.M., S.B. MacKenzie, J.-Y. Lee, and N.P. Podsakoff, "Common method biases in behavioral research: A critical review of the literature and recommended remedies", Journal of Applied Psychology 88(5), 2003, pp. 879-903.

[52] Fornell, C., and D.F. Larcker, "Structural Equation Models with Unobservable Variables and Measurement Error: Algebra and Statistics", Journal of Marketing Research 18(3), 1981, pp. 382-388.

[53] Hair, J., C.L. Hollingsworth, A.B. Randolph, and A.Y.L. Chong, "An updated and expanded assessment of PLSSEM in information systems research", Industrial Management \& Data Systems, 2017.

[54] Prasad, A., and P. Green, "Governing cloud computing services: Reconsideration of IT governance structures", International Journal of Accounting Information Systems 19, 2015, pp. 45-58.

[55] Vithayathil, J., "Will cloud computing make the Information Technology (IT) department obsolete?", Information Systems Journal 28(4), 2018, pp. 634-649.

[56] Morkevicius, A., and S. Gudas, "An Approach: A Service-Oriented Functional Business and IT Alignment", Information and Software Technologies, Springer Berlin Heidelberg (2012), 162-175. 